NBER WORKING PAPER SERIES

THE OPTIMAL PROBABILITY AND MAGNITUDE OF FINES FOR

ACTS THAT ARE DEFINITELY UNDESIRABLE

Louis Kaplow

Working Paper No. 3008

http: I/ www. nber. org/papers / w 3008

NATIONAL BUREAU OF ECONOMIC RESEARCH

1050 Massachusetts Avenue

Cambridge, MA 02138

June 1989

Harvard Law School and the National Bureau of Economic Research. I am grateful for comments by Lucian Bebchuk, Richard Craswell, A. Mitchell Polinsky, and Steven Shavell. This paper is part of NBER's program in Taxation. Any opinions expressed are those of the author not those of the National Bureau of Economic Research. 
NBER Working Paper \#3008

June 1989

\title{
THE OPTIMAL PROBABILITY AND MAGNITUDE OF FINES FOR ACTS THAT ARE DEFINITELY UNDESIRABLE
}

\begin{abstract}
Even when society would wish to deter all acts of some type, such as tax evasion and many common crimes, the benefits from deterrence often will be insufficient to justify the expenditures on enforcement that would be required to deter everyone. If some individuals are not deterred, however, they will bear risk when fines are employed as a sanction. As a result, it may be optimal to reduce total risk-bearing costs by reducing the number of individuals who bear any risk. This can be accomplished by increasing enforcement above the level that would be justified considering only the benefits of deterrence and the direct costs of enforcement. Another possibility is that it may be optimal reduce the risk borne by those who act, by employing fines below the maximum feasible level. This latter result constitutes an instance in which the well-known implication of Becker's analysis that it is optimal to employ extreme sanctions for all offenses is invalid.
\end{abstract}

Louis Kaplow

Harvard Law School

Griswold Hall-Room 402

Cambridge, MA 02138 
Society wishes to deter all individuals from committing some types of acts, such as tax evasion and many common crimes, for which the harm done exceeds any legitimate private benefits. Because enforcement is costly, however, complete deterrence often will not be desirable, at least on deterrence grounds alone. Individuals who are not deterred will bear the risk of sanctions - - here fines. If individuals are risk-averse, risk-bearing costs are incurred and must be taken into account in determining optimal enforcement policy.

One strategy would be to reduce the risk borne by those who are not deterred. Thus, it may be optimal to employ fines below the maximum feasible level, perhaps at the same time spending more on enforcement to maintain deterrence. This latter prescription is contrary to the well-known suggestion, with roots in Becker's (1968) analysis, that optimal enforcement involves achieving the appropriate expected sanction through a fine that is as high as possible (equal to a person's entire wealth) and a probability of detection that is correspondingly low, so as to economize on enforcement costs. ${ }^{1}$ This motivation for less-than-extreme sanctions supplements the previously developed argument of Polinsky and Shavell (1979) addressed to the case in which some individuals ideally are not deterred, such as those who efficiently breach contracts or who are subject to strict liability for their acts. Their argument and that developed here each offer reasons why, even when enforcement is optimal, individuals will commit acts and thus bear risk.

Another strategy to reduce total risk-bearing costs would be to reduce the number of individuals who bear any risk. This may be accomplished by increasing enforcement beyond the level that would be justified based upon a 
consideration of only the benefits of deterrence and direct costs of

enforcement. In some cases, complete deterrence may be optimal in light of the benefits of eliminating all risk-bearing costs.

Section 1 presents the model, which is analyzed in section 2 . Section 3 comments on the significance of the results.

\section{The Model}

Individuals decide whether to commit a harmful act based on whether it will maximize their expected utility. Individuals' benefits from committing the act differ, and are not observable by the social authority. Acts are subject to fines, which are imposed with some probability. ${ }^{2}$ Fines cannot exceed individuals' available wealth. Enforcement is financed by fine revenues and a lump-sum tax. The following notation is employed:

$h=$ total harm caused by each act, borne evenly by all individuals. ${ }^{3}$

$b$ - benefit to an individual from committing the act." $f(\cdot)$ - distribution (continuous or discrete) of b on $[0, h]$. $F(\cdot)=$ cumulative distribution function for $f(\cdot)$.

$U$ - utility of wealth.

$y=$ initial wealth.

2 It is assumed that individuals cannot insure against the fine. If they could insure at an actuarially fair rate, individuals intending to act would purchase complete coverage, making the analysis as in the risk-neutral case. This may increase achievable welfare by eliminating risk-bearing costs. (In example 1, below, although the optimum involves no risk-bearing costs when individuals were risk-averse, greater enforcement costs were incurred to deter acts that produced no net social harm.) In addition, the availability of insurance may reduce achievable welfare, because risk-aversion allows a given level of deterrence to be achieved at a lower probability of detection. (In example 1, below, if one assumes instead that $\alpha-.3$, full deterrence could be achieved at a probability below .0075, implying an enforcement cost less than that required to deter only the low-harm types when individuals are riskneutral.)

3 One can imagine an externality with such a property or that the harm is borne with equal probability by all individuals, with individuals purchasing actuarially fair insurance.

4 The analysis, for the most part, assumes that both $b$ and $h$ are monetizable - that is, they are to be taken into account in computing the maximum feasible fine. All the results hold if either or both factors are nonmonetizable. 


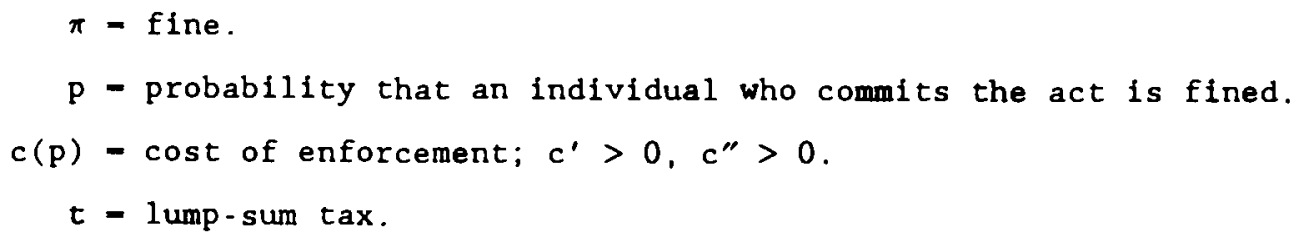

Begin by considering an individual's maximization problem. For those who do not act, wealth is given by

which is initial wealth minus the tax owed minus the harm caused. The portion who are deterred is $F\left(b^{*}\right)$, where $b *$ refers to the type of individual who is just indifferent between acting and not acting - that is, the type for whom

$$
(1-p) U(x+b)+p U(x+b-\pi)=U(x)
$$

Given $b^{*}$, the expected utility if one acts (the left side of (2)) is increasing in $b$ and the utility if one does not act (the right side) is independent of $b$, so all individuals for whom $b>b *$ will act and all for whom $b<b *$ will not act. ${ }^{5}$

The social authority, which does not observe individuals' types, ${ }^{6}$ chooses $p$ and $\pi$ to maximize social welfare, defined as the sum of individuals' expected utilities,?

\footnotetext{
5 There need not exist or be a unique $b *$ that solves (2). (Existence is the lesser complication as, for $b *=0$, the right side of (2) is greater the left, and conversely for $b * \geq \pi$, so there will exist a b* with the properties described in text even if (2) does not hold for such a b*.) For the riskneutral case and the constant absolute risk aversion utility function used to prove the results, however, there exists a unique $b *$.

6 It is obvious that, when it would be ideal for some individuals to engage in an activity, it would be optimal to excuse them from sanctions whenever sanctions are costly - - and imposing risk is a relevant cost. The results here imply that, for the same reason, if individuals' types could be observed, it would tend to be optimal to excuse even those who, ideally, should not act, if their benefits are high enough that they are not deterred at the optimum. In addition to avoiding the risk-bearing costs at a given $p$ and $\pi$, one could raise $\pi$ and lower $p$, thus achieving more cost-effective deterrence.
}

For the discrete case, substitute the summation for the integral. 
(3) $W-\int_{0}^{b *} U(x) f(b) d b+\int_{b *}^{h}[(1-p) U(x+b)+p U(x+b-\pi)] f(b) d b$,

subject to the constraints that the lump-sum tax finances the required

enforcement expenditures net of the fine revenue collected.

(4) $t=c(p)-(1-F(b *)) p \pi$,

and that the fine not exceed individuals' available wealth. The maximum feasible fine, $\hat{\pi}$, can be expressed as

(5) $\hat{\pi}=y-c(p)+(1-F(b *)) \hat{p} \pi-(1-F(b \star)) h+b *$,

where $b *$ refers to the type of individual who is just indifferent at $p, \hat{\pi}$.

This simply is initial wealth minus the tax and harm imposed, plus the benefit of the marginal individual. ${ }^{8}$ This formulation assumes that the harm and benefit are both monetizable. ${ }^{9}$

Before proceeding, it is helpful to consider briefly the (admittedly unrealistic) case in which there is no limit on the maximum feasible fine. For any given fine and probability of detection, one can reduce enforcement costs while achieving the same degree of deterrence by reducing the probability of detection and increasing the fine by an appropriate amount. Thus, it will be optimal to deter everyone at negligible cost with a vanishingly small probability and a correspondingly high fine. ${ }^{10}$ Because all individuals are deterred at the optimum, no risk is borne. This result contrasts with that of Polinsky and Shavell (1979) because they examined acts

\footnotetext{
8 See Kaplow ( $1989 \mathrm{~b}$, note 26 ) with regard to the statement of the maximum feasible fine as being the same for all types of individuals.

9 This may be appropriate for instances such as tax evasion, where the harm may derive from higher payments required from some other tax and the benefits may be saved taxes net of resources expended in evasion. All the results hold if either or both are not monetizable.

10 To demonstrate this, note first that, for any $p>0$, the optimal fine is any that is sufficiently high to deter everyone: A lower fine would result in some net harm, in which case aggregate expected income would be lower and it would not be distributed equally (whereas, when all are deterred, all have equal income); thus, with concave utility, welfare must be lower. Given that all are deterred, from (3) one has, for $\mathrm{p}>0, \mathrm{dW} / \mathrm{dp}=-\mathrm{c}^{\prime} \mathrm{U}^{\prime}<0$. Finally, for $p$ sufficientiy small (but positive), welfare must exceed that at $p-0$ so long as all the population (except a group of measure zero) is not of type $\mathrm{b}=\mathrm{h}$.
} 
for which some individuals benefited by more than the harm caused; in that case, the optimum in the risk-neutral case involved a sanction sufficient to deter only those whose act caused more harm than benefit. When individuals are risk-averse, the risk-neutral solution - - in which individuals with high benefits continue to act - entails such individuals bearing risk. Taking this cost into account can produce qualitatively different results. It might have appeared that the existence of "desirable illegal acts" was necessary for this issue to arise. In fact, however, a constraint on the maximum feasible sanction (which in practice will always exist) is sufficient to yield fundamentally different results.

\section{Analysis}

This section begins by stating the results and discussing the intuition for each. Then the propositions are demonstrated by constructing two discrete examples having the required properties. ${ }^{11}$ The case when individuals are risk-neutral is examined briefly because the solution of that case isolates the benefits of deterrence and costs of enforcement. Differences in the optimum when individuals are risk-averse can thus to attributed to risk aversion rather than to other considerations.

\section{A. Results}

(1) When individuals are risk-averse, a probability of detection sufficient to deter all individuals may be optimal even when full deterrence would not be optimal if individuals were risk-neutral. In such a case, the optimal probability will be the lowest for which full deterrence is feasible and the optimal fine will be the maximum feasible fine (equal to total wealth). (See example 1.) When individuals are risk-neutral, it is not optimal to deter those with benefits sufficiently close to the level of harm, because the benefits of deterrence become arbitrarily small while the marginal

11 The continuous case, examined in Kaplow (1989b), is substantially more complex, but in ways that do not affect the basic results; thus, it is not examined here. 
cost of deterrence does not. When individuals are risk-averse, however, increased deterrence reduces the number of individuals who bear risk and thus may justify expenditures that are not justified on deterrence grounds alone. In particular, deterring all individuals may be optimal because, at the margin, the savings in risk-bearing costs are positive, and thus may exceed the positive marginal enforcement costs. ${ }^{12}$ And, if it is optimal to deter all individuals, the most efficient way to accomplish this will involve employing the lowest probability for which this is feasible and the maximum feasible fine. This extreme sanction will impose no risk-bearing costs because no one ever bears the sanction.

(2) When individuals are risk-averse, it may be optimal to deter some but not all individuals. When this is the case, it may be optimal to impose a fine lower than the maximum feasible fine. (See example 2.) Because expenditures on enforcement are subject to diminishing returns, it may be that the harm of an act is sufficiently great to justify some expenditures on enforcement (despite the imposition of risk-bearing costs) while the costs of complete deterrence are sufficiently high that the result in (1) will not hold. Thus, partial deterrence may be optimal. In such instances, undeterred individuals bear risk, so it may be efficient to spend additional resources to reduce risk-bearing costs. For a given level of deterrence, risk-bearing costs may be reduced by decreasing the fine and correspondingly increasing the probability of detection, the latter entailing enforcement costs. Whether a fine below the maximum feasible level will be optimal depends on whether the marginal savings in risk-bearing costs exceed the required marginal increase in enforcement resources.

(3) When individuals are risk-averse, optimal enforcement may involve a higher or lower probability of detection, a higher or lower fine, and a higher

12 This analysis implies that, even if some individuals' benefits exceed harm, but not by a significant amount, it may be optimal to deter them: marginal deterrence benefits would be negative, rather than zero as in the case in text, and marginal enforcement costs would be positive, but the sum of these effects could still be less than the marginal savings in risk-bearing costs. This result and that in text is analogous to the suggestion in Polinsky and Shavell (1984) that when imprisonment (which is socially costly to impose) is the sanction, overdeterrence may be optimal because it decreases sanctioning costs. 
or lower level of deterrence than when individuals are risk-neutral. A higher probability of detection may be optimal than when individuals are risk-neutral either because of the benefits from reducing risk-bearing costs when only some are to be deterred, as described in the discussion of (2), ${ }^{13}$ or in order to deter more individuals to reduce the portion of the population subject to risk-bearing costs, as noted in the discussion of (1). A lower probability may be optimal because one can achieve equivalent or greater deterrence at lower probabilities when individuals are risk-averse. (See example 2.)

A lower fine may be optimal when individuals are risk-averse in order to reduce risk-bearing costs, as discussed with result (2). A higher fine may be optimal despite the fact that the risk-neutral case involves imposition of the maximum feasible fine, because the maximum feasible fine when individuals are risk-averse may be greater. (See example 1.14)

Greater deterrence may be optimal when individuals are risk-averse because, as described in result (1), a lower fraction of the population is subject to risk-bearing costs. Because all are deterred when result (1) applies, there does not exist the countervailing effect that those not deterred would incur greater risk-bearing costs. This latter effect suggests that lower deterrence also may be optimal when individuals are risk-averse. ${ }^{15}$

\section{B. Examples}

For each, choose parameters and functions as follows:

$h=1$.

$b \in(.1,1)$.

$f$ is discrete; $f(.1)=.9, f(1)=.1$.

13 In example 2, a higher probability than when individuals are risk-neutral is not required to accomplish this because of the strength of the countervailing effect noted in the text to follow. For different parameter values, a higher probability may be necessary for this reason. See Kaplow
(1989b).

14 Because more harm is prevented and the type just indifferent is higher when deterrence is higher, the maximum feasible fine is higher despite greater enforcement costs and lower fine revenue.

15 That lower deterrence may be optimal is the only result not illustrated by either example. For a demonstration of this possibility, see kaplow (1989b). 


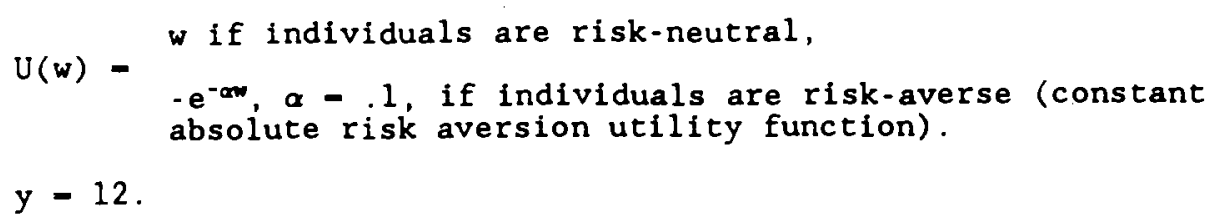

Individuals are risk-neutral: When individuals are risk-neutral, it is familiar that the maximum feasible fine is optimal, for otherwise one could increase the fine and reduce the probability of detection, keeping $p \pi$ constant, which would reduce enforcement costs without changing behavior. Thus, all that remains is to determine the optimal level of enforcement. Clearly, it is not optimal to deter individuals for whom $b-1$, for their benefit equals the harm caused, and additional resources must be expended to deter them. Thus, the optimum entails $b *=.1$ or $b *=0$. For the former, the result is $p \approx .0083, \hat{\pi} \approx 12.01$. At this $p, c \approx .000000004$, which is less than the net benefit of .81 from deterring individuals for whom $b=.1$, so this is the optimum. (The net harm caused by each is $h-b=1-.1=.9$ and they constitute .9 of the population.)

Individuals are risk-averse: For the stated utility function, using (2), the marginal type can be expressed as (6) $e^{\alpha b *}-1-p+p e^{\alpha \pi}$.

If all are to be deterred, the maximum feasible fine is optimal for the same reason as when individuals are risk-neutral. (Since all are deterred, the high fine does not result in any risk-bearing costs.) For the parameters given, one has $\mathrm{p} \approx .0394, \hat{\pi} \approx 13$. Enforcement costs are approximately .0000024 . Because the net harm avoided, as when individuals are risk-neutral, is .81 , this option is superior to deterring no one. (Aggregate expected income is greater and it is distributed equally.) The other possibility is to deter only individuals for whom $b *-.1$. If that is optimal, one should select a probability and fine so that, in (6), one just has $b *-.1$, for if b* were greater one could reduce $\pi$ and impose less risk. For b* -.1 to be superior to $b *-1$, the savings in enforcement costs would have to exceed the resulting risk-bearing costs. At b* -.1 , however, total risk-bearing costs 
must exceed .001 if any enforcement costs are to be saved, so this is not possible. ${ }^{16}$ Thus, it is optimal to deter all individuals - including the type that causes no net harm - to avoid risk-bearing costs.

Example 2: c(p) $-(25 p)^{4}$

Individuals are risk-neutral: As before, the possible optima are b* = 0 and $b *=.1$. For the latter, one has $p=.00833, \hat{\pi} \approx 12.01$, incurring enforcement costs under .002 . Net harm averted is .81 , so again the optimum involves deterring the $1 n w-b e n e f i t$ types.

Individuals are risk-averse: To deter everyone requires a probability in excess of .0394 , which costs more than .94 . As the total (not net) harm averted is 1 , the net gain is under .06, which is less than the forgone benefits of both types from acting. Thus, deterring no one is pareto superior to deterring everyone. At $b *=.1$, one can compute that the optimal policy is $\mathrm{p} \approx .006, \pi \approx 9.84$. Because this involves costs of approximately .0005, and saves harm of .9 , both groups are better off than if no one is deterred. (Type . 1 saves harm of .9 and loses a benefit of .1 and pays a tax less than the cost of .0005. Type 1 saves harm of .9, pays a tax less than .0005, and is subject to a fine with a money-equivalent cost of .1 with this utility function. ") Interestingly, the optimal fine of 9.84 is less than the maximum feasible fine at this probability, which is approximately 11.9. The reason is that reducing $\pi$ while increasing $p$ in a manner that maintains the same deterrence reduces risk-bearing costs. The optimal fine is not even lower than 9.84 because increasing $p$ also raises enforcement costs. The

\footnotetext{
16 For a given b*, risk-bearing costs are reduced as $p$ is increased and $\pi$ is correspondingly reduced. If $p$ exceeds. 0394 , however, there is no savings in enforcement costs, so deterring everyone (which entails no risk-bearing costs) would be superior. At $p=.04$, the necessary fine to deter type.1 is approximately 2.24. The certain reduction in income for type 1 individuals making them indifferent to $\mathrm{p} \pi$ is, with this utility function, simply b*. The difference between that reduction (.1 in this instance) and the transfer $(\mathrm{p} \pi=.04 \times 2.24=.0896)$ of .0104 is the risk-bearing cost incurred by .1 of the population, so total risk-bearing costs exceed .00104 . (Note that deterring only the type with $b=.1$ also entails an unequal distribution of income which, with concave utility, reduces welfare further.)

17 See note 16 .
} 
intermediate result ( $f$ ine below maximum feasible fine, probability less than one) reflects the optimal trade-off of these factors.

\section{Concluding Remarks}

(a) For many crimes, tax evasion, and some other acts, it would be ideal (or, at least, approximately so) for no individuals to commit the acts. It is often the case, however, that a probability sufficient to deter all individuals would be extremely expensive. If partial deterrence is thus employed, undeterred individuals bear risk. Optimal enforcement policy will take this cost into account. One strategy involves reducing the number of individuals who bear risk by increasing enforcement above the level that would be warranted based on considerations of deterrence and enforcement costs alone. As in one of the examples presented, it even may be optimal on these grounds to expend resources to deter individuals whose acts produce benefits equal to their social costs.

Another strategy involves reducing the risk borne by individuals who are not deterred. Thus, it may be optimal to employ fines below the maximum feasible level, possibly with corresponding increases in enforcement expenditures. This result is similar to that in Polinsky and Shavell (1979), where the reason some individuals optimally were not deterred was that socially beneficial acts as well as harmful ones were subject to sanctions (as in the case of breach of contract and acts subject to strict liability). For most offenses, one indeed observes fines far less than most violators' wealth. While consistent with the results presented here and in Polinsky and Shavell, these practices are unlikely to be justified by the concern for avoiding riskbearing costs in contexts in which the fine is so low that the marginal riskbearing costs from a slightly higher fine would be trivial.

(b) In light of this analysis, it seems inappropriate when analyzing optimal enforcement policy simply to assume, as is commonly done, that the fine is fixed at some stated level - - whether an absolute amount or some rate to be multiplied by a measure of the severity of the infraction. ${ }^{18}$ The 
optimal fine will be a function of the other instruments under study, and the entire character of the optimum with regard to other instruments (here, the probability of detection) may differ when the fine is set optimally rather than stipulated.

(c) Many explanations have been offered for the commonly observed practice of using fines far below individuals' wealth. Most prominent is the notion that fines must in some sense be proportional to the harm caused by an activity. See Stern (1978). Usually, little normative defense is offered for such claims and the appropriate proportion is unstated. Actual practice varies widely in this respect. For example, a $\$ 10$ fine for failing to put $10 \mathrm{f}$ in a parking meter is a fine of 10,0008; civil tax fraud (not mere mistake or negligence) - - which most would consider a worse offense - has a fine, in addition to repayment, of under 1008. Double parking may be subject to a fine of $\$ 30$, an infinite percent of the actual harm caused in many instances. If a serious accident results and one is successfully sued for negligence, one might have to pay $\$ 1,000,000 \ldots$ which is no penalty beyond actual harm caused but a penalty of, perhaps, more than 3,000,0008 of the expected harm. Thus, it is extremely difficult to infer from actual practice the content of this proportionality concept. Nonetheless, it seems that such beliefs are widespread.

A less frequent, but quite plausible explanation for moderate penalties is that some offenses are committed by mistake. ${ }^{10}$ One may forget to put money in a parking meter or not understand the income tax rule one violated in filing a tax return. In such instances, high fines may have little additional

18 It is not obvious that a wealth constraint would justify a constant penalty rate. Moreover, when there is no limit to the severity of the infraction, or the only limit (as with tax evasion) is one's wealth, a constant penalty rate is infeasible.

19 See Kaplow (1989a) on this case. Another reason sometimes offered for moderate fines is that marginal deterrence must be preserved. This is at best a weak argument even against fines approaching total wealth, as imprisonment remains available. In addition, for fines well less than total wealth but far above currently observed fines, it is difficult to understand the marginal deterrence problem. Since the fine is only imposed when individuals are detected, and in many instances apprehension and collection could follow almost immediately and automatically, one does not confront the problems that arise in such cases as the kidnapper who, faced with capital punishment for the offense, may be left with little incentive not to kill the victim. 
deterrent effect but impose great risk on violators. If there is a significant group who make such mistakes -- or, alternatively, who act intentionally but mistakenly underestimate the fine or probability of detection - a very high fine could produce substantial risk-bearing costs. The more efficient policy may be to expend more resources on detection and impose lower penalties, even to such a degree that some intentional and informed violators will remain undeterred. Note that this explanation has much in common with that explored in the model here. One could, in principle, expend enough resources i:o educate the entire population so that few made mistakes. ${ }^{20}$ But this often would be quite costly. The uninformed group is much like those individuals in the model here that had high private benefits and thus remain undeterred at the optimum, even though they were assumed to be fully aware of the consequences.

20 Higher penalties might induce individuals to be more careful or to learn more about applicable rules, but such responses are themselves costly and may be incomplete. 


\section{REFERENCES}

Becker, Gary S., Crime and Punishment: An Economic Approach, Journal of Political Economy 76, March/April 1968, 169-217.

Kaplow, Louis, Optimal Enforcement When Some Individuals Are Uninformed about the Law, 1989a.

The Optimal Probability and Magnitude of Fines for Acts That Are Definitely Undesirable, Harvard Program in Law and Economics Discussion Paper No. 55, $1989 \mathrm{~b}$.

Polinsky, A. Mitchell and Shavell, Steven, The Optimal Tradeoff Between the Probability and Magnitude of Fines, American Economic Review 69, 1979, $880-891$

and The Optimal Use of Fines and Imprisonment, Journal of Public Ecoñomics 24,'1984, 89-99.

Stern, N., On the Economic Theory of Policy Towards Crime, in Heineke, J.M., ed, Economic Models of Criminal Behavior, North-Holland, Amsterdam, 1978, $123-152$. 